working with clients with borderline personality disorder in the lower North Island of New Zealand. It is a servicewide intervention with a long-term perspective, providing stabilisation and containment for both patient and staff. It is encapsulated in a management plan - a behavioural intervention to minimise reinforcement of hazardous behaviours and promote self-responsibility.

The plan defines the treatment system (e.g. psychiatric team, family, police, accident and emergency department staff), contains an acceptance of risk and explains the dangers of risk-averse responses from the service (Maltsberger, 1994). This breaks the cycle of assuming responsibility for the client and replaying a traumatising parent-child dynamic, with subsequent regression, increased risk and institutionalisation. We found that this is achieved through the process of writing and implementing the plan and it enables patients to move towards autonomous functioning. It must be agreed to by all involved and regular review meetings provide a forum for staff to own and manage their differences. Each plan should be an individualised document written by the case manager in consultation with the client; however, we have designed a template for ease of use. This work grew from the ideas of Krawitz \& Watson (1999) around the use of brief admissions as a successful part of long-term management, and the observation that the majority of work by outof-hours services involved these 'revolving door' patients. As yet, our approach has been validated only by empirical evidence. A paper is currently in preparation.

Krawitz, R. \& Watson, C. (1999) Borderline Personality Disorder: Pathways to Effective Service Delivery and Clinical Treatment Options. Wellington: Mental Health Commission of New Zealand.

Linehan, M. (1993) Cognitive Behavioural Treatment of Borderline Personality Disorder. New York: Guilford Press.

Maltsberger, J.T. (1994) Calculated risk taking in the treatment of intractably suicidal patients. Psychiatry, 57, 199-212.

Verheul, R., van den Bosch, L. M. C., Koeter, M.W. J., et al (2003) Dialectical behaviour therapy for women with borderline personality disorder. 12-month, randomised clinical trial in The Netherlands. British Journal of Psychiatry, 182, 135-140.

T. Flewett, P. Bradley, A. Redvers Personality Psychotherapy Service, PO Box 1729, Wellington, New Zealand

\section{Cognitive analytic therapy}

The review by Marks (2003) of our book Introducing Cognitive Analytic Therapy: Principles and Practice (Ryle \& Kerr, 2002 ) is both rude and misleading. His reminiscences about a visit to Leningrad in 1966 have nothing to do with the book and we certainly do not see 'Pavlovian therapy' (with which we are entirely unfamiliar) as 'part of cognitive analytic therapy (CAT)'. His objection to the fact that our explicitly integrative model draws on a wide range of sources tells us more about the limitations of his own conceptual framework than about CAT. These limitations are also evident in his inability to understand or unwillingness to mention the key features of CAT, which he seriously misrepresents. These include: (a) focus on 'reciprocal role procedures', which are formed though the internalisation of socially meaningful, intersubjective experience and subsequently determine both interpersonal behaviours and selfmanagement; and (b) the practical emphasis on the joint creation of descriptions of these, which serve to enlarge patients' capacity for self-reflection and change and therapists' ability to provide reparative, non-collusive relationships.

The reviewer's bias is epitomised in his discussion of one of the case histories in the book (pp. 138-144). While asserting that this 'patient with obsessive-compulsive rituals' would have been better served by nine sessions of behavioural therapy or by one session plus computer-aided therapy, he fails to record that the patient was presented precisely to illustrate the limitations of cognitive-behavioural approaches and does not mention that she had previously dropped out of an anxiety-management group and of cognitive-behavioural treatment. Of this she had noted that the more her symptoms were worked on, the 'more grimly' she hung onto them. This was not a report of the treatment of obsessivecompulsive rituals, it was a summary of the psychotherapy of a person, an unhappy woman with a history of many years of panic, phobias, obsessive-compulsive behaviours and irritable bowel syndrome. The case was chosen, in part, to demonstrate how focus on presenting symptoms can actually be counterproductive and paradoxically collude with the enactment of underlying reciprocal role procedures in a patient who had come to be regarded as 'difficult' and 'resistant'. This patient's list of 'target problem procedures', as worked out with her, included a pervasive need to control both her feelings and other people's behaviours. As is usual in CAT, this formulation, and her therapy, focused on intra- and interpersonal attitudes, assumptions and behaviours (procedures) and paid little direct attention to her symptoms. Therapy included, importantly, work on reciprocal enactments with the therapist. Assessment at termination and follow-up showed major improvements in her life, and psychometric testing demonstrated reductions in symptoms at termination with further reductions at 6-month follow-up.

We think it unfortunate that so obviously partisan a reviewer was selected to discuss a book outside his area of expertise and sympathy and that it was considered appropriate to publish so tendentious a review of the work of colleagues.

Marks, I. (2003) Book Review: Introducing Cognitive Analytic Therapy (A. Ryle \& I. B. Kerr). British Journal of Psychiatry, 182, 179-180.

Ryle, A. \& Kerr, I. B. (2002) Introducing Cognitive Analytic Therapy: Principles and Practice. Chichester: John Wiley \& Sons.

A. Ryle CPTS, Munro Centre, Guy's Hospital London SEI 9RT, UK

I. B. Kerr Community Health Sheffield NHS Trust, Limbrick Centre, Sheffield, UK

\section{Cinders, you shall go to the ball}

Goodwin has described bipolar disorder as the Cinderella of psychiatry, largely on the basis of his study showing the relative paucity of research studies in bipolar disorder compared with schizophrenia (Goodwin, 2000). This study has been reinforced by Clement et al (2003), who similarly concluded that bipolar disorder is underrepresented compared with schizophrenia and that this disparity is not declining over time. The importance of this discrepancy is demonstrated by the finding that bipolar disorder causes a greater global burden of disease than schizophrenia (Murray \& Lopez, 1997) and by the huge financial impact of bipolar disorder on society (Das Gupta \& Guest, 2002)

Clement and colleagues appear to lay the responsibility for the relative lack of bipolar research on a national shortage of specialist clinical services and on the lack of interest of researchers. However, clinical services such as our own in the Northern Deanery are flourishing and we suggest that historical difficulties in obtaining public 
funding for bipolar disorder are of greater impact. Clement et al examined citations in 5-year periods from 1966 to 2000. However, examination of Medline citations on an annual basis between 1996 and 2002 shows that the relative difference between research in bipolar disorders and schizophrenia may be becoming smaller. It appears that this has not been driven by a change in priorities of public funding bodies but rather by the presence of a private organisation, the Stanley Medical Research Institute, which funds approximately half of all US studies in bipolar disorder and has provided US\$130 million for research since its inception in 1989. This timely report by Clement and colleagues should serve as a rallying call to governments and charitable funding bodies to give bipolar disorder the priority it demands.

\section{Declaration of interest}

The authors are supported in their research by the Staney Medical Research Institute.

Clement, S., Singh, S. P. \& Burns, T. (2003) Status of bipolar disorder research. Bibliometric study. British Journal of Psychiatry, 182, 148-152.
Das Gupta, R. \& Guest, J. F. (2002) Annual cost of bipolar disorder to UK society. British journal of Psychiatry, 180, 227-233.

Goodwin, G. (2000) Perspectives for clinical research on bipolar disorders in the new millennium. Bipolar Disorder, 2, 302-304.

Murray, C. \& Lopez, A. (1997) Global mortality, disability, and the contribution of risk factors: Global Burden of Disease Study. Lancet, 349, 1436-1442.

S. Watson, A. H. Young School of Neurology, Neurobiology and Psychiatry, University of Newcastle, Department of Psychiatry, The Royal Victoria Infirmary, Queen Victoria Road, Newcastle upon Tyne NEI 4LF, UK

\section{One hundred years ago}

\section{Insanity from hasheesh (extract) by John Warnock, MD, Medical Director, Egyptian Hospital for the Insane, Cairo}

In the report for the year 1899 of the Bengal asylums, it is stated that 45 out of 220 cases admitted were due to the use of Cannabis Indica.

In Egypt, statistics are available since the year 1895. During the six years 1896 1901, out of 2564 male cases of insanity admitted to the Egyptian Asylum at Cairo, 689 were attributed to the abuse of hasheesh, i.e., nearly 27 per cent. Very few female patients used hasheesh, and it is noteworthy that insanity is more than three times as common among the hasheesh-using sex as among women, who, comparatively, seldom use the drug.

I think this difference in the insanity rate between the sexes is significant, and goes a long way to prove the importance of hasheesh as a cause of insanity among Egyptian men. Let it also be remembered that in England insanity is more frequent among women than among men (35 to 31).

My experience does not confirm the Indian Commission's belief that Cannabis Indica only sometimes causes insanity. In Egypt it frequently causes insanity. As to whether excessive use of hemp drugs is commoner here than in India I can give no opinion, but many thousands use it daily here. Probably only excessive users, or persons peculiarly susceptible to its toxic effects, become so insane as to need asylum treatment. Whether the moderate use of hasheesh has ill effects I have no means of judging, and this paper is now read to elicit the opinions of my colleagues in Egypt, whose daily practice must give them opportunities of studying the effects of the ordinary use of hasheesh. I should be grateful for information on this question.
I have never met with dysentery or bronchitis as the direct result of the use of hasheesh.

Again, in my experience, I find that persons insane from hasheesh have a proneness to commit crimes, especially those of violence, and I have a strong suspicion that much disorderly conduct results from hasheesh smoking, just as alcohol among Europeans leads to such misconduct.

To sum up, the use of Cannabis Indica in Egypt seems to have graver mental and social results than in India, and is responsible for a large amount of insanity and crime in this country.

\section{REFERENCE}

Journal of Mental Science, January 1903, 109-110.

Researched by Henry Rollin, Emeritus Consultant Psychiatrist, Horton Hospital, Epsom, Surrey

\section{Corrigenda}

Adolescent precursors of cannabis dependence: findings from the Victorian Adolescent Health Cohort Study. BJP, 182, 330-336. The full reference to Patton et al (2002) should read: Patton, G. C., Coffey, C., Carlin, J. B., et al (2002) Cannabis use and mental health in young people: cohort study. BMJ, 325, 1195-1198.

Non-right-handedness and schizophrenia (letter). BJP, 181, 349-350. The first sentence of the last paragraph should read: In schizophrenia, I have suggested that the gene may lose its directional coding and become 'agnosic' for right or left.

Long-term outcome of long-stay psychiatric in-patients considered unsuitable to live in the community. TAPS Project 44. BJP, 181, 428-432. Table 1 (p. 430) should read: 